Elżbieta Bender (D)

Uniwersytet Marii Curie-Skłodowskiej, Lublin

e.bender@op.pl

\title{
Miguel de Unamuno y Vida de Don Quijote y Sancho: lector real y refundición de la obra cervantina
}

\section{Resumen:}

En este artículo, enmarcado en la teoría de la recepción, se subraya la importancia del lector en la actualización de una obra literaria. A través del análisis del libro de Miguel de Unamuno Vida de Don Quijote y Sancho se evidencia cómo las experiencias personales del lector influyen en la interpretación de una obra literaria, llegando a dotarla de nuevos significados.

En Vida de Don Quijote y Sancho Miguel de Unamuno crea su personal e intimísima versión de la novela de Cervantes. La lectura del Quijote le lleva a ahondar en los temas clave de su quehacer literario y filosófico: inmortalidad, religión, amor, justicia.

Palabras clave: Unamuno, Vida de Don Quijote y Sancho, lector, teoría de la recepción, el Quijote

\section{Abstract:}

Miguel de Unamuno and The Life of Don Quixote and Sancho: Real Reader and the Adaptation of the Cervantes's Work

The article, within the framework of the reception theory, emphasizes the importance of the reader in the updating of a literary work. The analysis of Miguel de Unamuno's book The Life of Don Quixote and Sancho demonstrates how the personal experiences of the reader influence the interpretation of a literary work, providing it with new meanings. 
In The Life of Don Quixote and Sancho, Miguel de Unamuno creates his personal and very intimate version of Cervantes's novel. The reading of Don Quixote makes Unamuno delve deeper into the key topics of his literary and philosophical works: immortality, religion, love, justice.

Keywords: Unamuno, The Life of Don Quixote and Sancho, reader, reception theory, Don Quixote

En 1905, trescientos años después de la primera edición de la novela cervantina El ingenioso hidalgo Don Quijote de la Mancha, Miguel de Unamuno publicó un peculiar libro, fruto de sus divagaciones acerca de la lectura de las aventuras del famoso hidalgo. Su obra, titulada Vida de Don Quijote y Sancho no era sin embargo su primer texto dedicado a los protagonistas cervantinos, pero sí el más extenso y el más importante. Pues, según Jesús G. Maestro (1989: 241), hasta el año 1905 Unamuno escribió siete textos sobre la materia quijotesca: „Quijotismo" (1895), "El caballero de la Triste Figura. (Ensayo iconológico)” (1986), “¡Muera don Quijote!” (15 de abril de 1898), “ ¡Viva Alonso el Bueno!” (1 de julio de 1898), "Más sobre don Quijote" (6 de julio de 1898), "Glosas al «Quijote»" (1902), "La causa del «Quijote»" (1903), "Sobre la lectura e interpretación del «Quijote»" (1905). Después de 1905 escribió otros tantos. Además, en varios ensayos suyos, centrados en una temática sin ninguna relación con la novela cervantina, Unamuno hizo no pocas referencias a la figura de Don Quijote. Tal es el caso de los ensayos En torno al casticismo, publicados primero en 1895 en la revista La España moderna y siete años más tarde recogidos en forma de libro.

La cantidad tan considerable de textos sobre El Quijote en la obra unamuniana y su extraordinaria escrupulosidad analítica son prueba del gran impacto de la obra cervantina en el quehacer literario y filosófico de Unamuno.

De entre todos los escritos unamunianos sobre El Quijote destaca el libro Vida de Don Quijote y Sancho. Es un texto que resulta realmente difícil de clasificar. No es ensayo, ni comentario. Tampoco es crítica 
literaria, aunque algunos investigadores cervantistas lo quieren ver como tal. Por ejemplo, Jesús Maestro (1989: 242) califica la Vida de Don Quijote y Sancho como "lectura e interpretación del Quijote", efecto de la recepción estética e ideológica. En cambio, Javier Blasco (2004: 56) opina que Unamuno se sirve del personaje de don Quijote tan solo para definirse a sí mismo y considera que la Vida de don Quijote y Sancho no es otra cosa que "el autorretrato del escritor bilbaino, adornado con toda una serie de valores (fe, valor, locura, pasión, etc.)".

A su vez el mismo Unamuno en Vida de don Quijote y Sancho declara explícitamente no tener intención de analizar metodológicamente el texto cervantino. Asegura:

dejo a eruditos, críticos literarios e investigadores históricos la meritoria y utilísima tarea de escudriñar lo que el Quijote pudo significar en su tiempo y en el ámbito en que se produjo y lo que Cervantes quiso en él expresar y expresó. (VQS: 96$)^{1}$

En otros fragmentos de la Vida de Don Quijote y Sancho comprobamos que para Unamuno es inútil averiguar lo que podría haber querido transmitir Cervantes, ya que era un escritor mediocre, por lo que no vale la pena prestar atención a las pistas que él mismo había dejado para la interpretación de su novela. Tan negativa valoración de Cervantes por parte de Unamuno se deja ver en varios escritos de este. Así, en una carta a Pedro de Múgica del 28 de diciembre de 1904 (Gullón, 1987: IV), Unamuno escribe que Cervantes era "un pobre diablo muy inferior a su obra" y, en lógica consecuencia, lo que quiso decir le tiene "completamente sin cuidado".

En el ensayo "Sobre la lectura e interpretación del Quijote", publicado en abril de 1905, entonces rigurosamente contemporáneo del libro, aparecen afirmaciones como las siguientes:

No me cabe duda de que Cervantes es un caso típico de un escritor enormemente inferior a su obra. [...] Cervantes se murió sin haber calado todo

${ }^{1}$ Todas las citas de Vida de Don Quijote y Sancho proceden de la edición Alianza Editorial del año 1987 y van acompañadas de las siglas VQS, seguidas del número de la página correspondiente. 
el alcance de su Quijote, y acaso sin haberlo entendido a derechas. Cada vez que el bueno de Cervantes se introduce en el relato y se mete a hacer consideraciones por su parte, es para decir alguna impertinencia o juzgar malévola y maliciosamente a su héroe.

[...] Cervantes, si no acabó de comprender a derechas a su Don Quijote, no empezó siquiera a comprender a su Sancho, y si fue con aquél malicioso algunas veces, fue con éste casi siempre injusto. A Sancho le calumnia y le maltrata sin razón ni motivo, se empeña en no ver claro los móviles de sus actos, y hay ocasiones en que se siente uno tentado a creer que, movido por esa incomprensión, altera la verdad de los hechos y le hace decir y hacer al buen escudero cosas que nunca pudo haber. (apud López-Pasarín Basabe, 2009: 57)

El escaso respeto que le merecía a Unamuno la figura de Cervantes se plasma también en una de las últimas páginas de la Vida de Don Quijote y Sancho:

No cabe duda sino que en El ingenioso hidalgo Don Quijote de la Mancha que compuso Miguel de Cervantes Saavedra se mostró éste muy por encima de lo que podríamos esperar de él juzgándole por sus otras obras... (VQS: 262)

Francisco La Rubia Prado (1999: 137-138) ve en la Vida de Don Quijote y Sancho una especie de "desafío a la figura de Cervantes". Lo confirman las palabras del prólogo de la edición de 1930, donde Unamuno se atreve a decir: "fue Cervantes el que leyó mal y que mi interpretación, y no la suya, es la fiel" (VQS: 96).

Convencido de entender mejor que Cervantes la historia del famoso hidalgo, en la Vida de Don Quijote y Sancho Unamuno elabora su personalísima versión de la novela. Lo que conserva del original cervantino es el protagonismo de los dos personajes clave -Don Quijote y Sancho Panza- y la estructura del libro, es decir, el orden de los capítulos y los títulos de los mismos. Todo lo demás son diferencias. La valoración de los episodios y de sus elementos constitutivos es casi siempre muy distinta a la de Cervantes. A menudo Unamuno llama la atención de un detalle - sin importancia en el Quijote de 
Cervantes- para reflexionar sobre temas que siempre le han preocupado, como la fe, la inmortalidad, el amor o la justicia. A veces, mientras reflexiona sobre una aventura de la novela cervantina, se fija en que le falta una información importante. Entonces trata de explicar la razón de dicha carencia y se extiende en divagaciones de carácter filosófico. Así, en el primer capítulo advierte que el retrato de Don Quijote carece de datos sobre nacimiento, infancia, juventud o linaje del hidalgo para casi enseguida encontrar explicación para tal descuido. Entonces recurre a un fragmento de la novela, que a primera vista debería esclarecer la procedencia de Don Quijote pero en realidad le sirve para subrayar que cada hombre es libre para actuar. Unamuno insiste, muy conforme con los preceptos del catolicismo, que el hombre se hace por medio de sus propios actos. Su vida y su destino depende más de él mismo que de su linaje o herencia:

Respecto a su linaje, declaró él mismo [Don Quijote] a Sancho departiendo con éste después de la conquista del yelmo de Mambrino, que si bien era «hijodalgo de solar conocido, de posesión y propiedad y de devengar quinientos sueldos», no descendía de reyes, aunque, no obstante ello, el sabio $^{2}$ que escribiese su historia podría deslindar de tal modo su parentela y descendencia que le hallase ser quinto o sexto nieto de rey. Y de hecho no hay quien, a la larga, no descienda de reyes, y de reyes destronados. Más él era de los linajes que son y no fueron. Su linaje empieza en él.

Es extraño, sin embargo, como los diligentes rebuscadores que se han dado con tanto ahínco a escudriñar la vida y los milagros de nuestro Caballero no han llegado aún a pesquisar huellas de tal linaje, y más ahora en que tanto peso se atribuye en el destino de un hombre a eso de su herencia. Que Cervantes no lo hiciera, no nos ha de sorprender, pues al fin creía que es cada cual hijo de sus obras y que se va haciendo según vive y obra [...]. (VQS: 26)

Otra importante diferencia entre la versión cervantina y la unamuniana de la historia de Don Quijote es que a Unamuno solo le

${ }^{2}$ Con este elogioso calificativo Unamuno se refiere a Cide Hamete Benengeli, historiador y primer autor de la historia de Don Quijote. 
interesan las aventuras de los dos principales protagonistas. En consecuencia quedan eliminadas las historias interpoladas, tan abundantes en la novela cervantina. Asimismo se saltan casi todos los capítulos metaliterarios, incluso cuando estos atañen muy directamente al mismo protagonista. Por ejemplo, Unamuno omite el capítulo sobre el famosísimo escrutinio de la biblioteca de Don Quijote realizado por el cura y el barbero. Como él mismo explica, "es crítica literaria que debe importarnos muy poco" (VQS: 50). El escritor bilbaino insiste una y otra vez en que Don Quijote y Sancho eran seres reales, por lo que el estudio de su historia - real y verdadera - debe huir de la crítica literaria. Sin embargo, Unamuno no permanece fiel a esta declaración suya: en varias ocasiones, mientras reflexiona sobre un tema, recurre a obras de la literatura clásica tanto española como extranjera. $\mathrm{Su}$ experiencia como lector se impone poderosamente, aunque eso sí, según insiste, menciona tan solo libros llenos de vida, anclados en la realidad. A veces Unamuno se pregunta si Don Quijote ha conocido algunos libros que a él le parecen importantes:

¿No conocía Don Quijote las palabras de Don Diego López de Haro, tal cual le hace hablar Tirso de Molina en la escena primera del acto segundo de La prudencia en la mujer, cuando empieza diciendo:

Cuatro bárbaros tengo por vasallos

A quien Roma jamás conquistar pudo,

Que sin armas, sin muros, sin caballos,

Libres conservan su valor desnudo? (VQS: 59)

La Vida de Don Quijote y Sancho refleja perfectamente cómo a través de la lectura se concretiza y se actualiza una obra literaria. Se subraya el papel decisivo del lector, su enorme poder para asignar nuevos significados a la narración del libro que lee. Por eso, según Jesús Maestro (1989), a Unamuno hay que verlo como precursor de la Rezeptionsasthetik o estética de la recepción, teoría nacida en Alemania a finales de los años sesenta del siglo XX. Ideada por Hans Robert Jauss, la teoría de la recepción impone buscar la experiencia literaria del lector allí donde ésta "entra en el horizonte de expectativas de su 
práctica vital, reforma su comprensión del mundo, y, con ello, incide también en su comportamiento social" (Maestro, 1989: 243).

Analizando la relación entre El Quijote de Cervantes y la Vida de Don Quijote y Sancho de Unamuno, Maestro trata de definir los factores histórico-literarios, que la estética de la recepción denomina como "horizonte de expectativas", es decir, todo lo implicado directamente en la obra, y como "horizonte de experiencias", es decir, lo suplido por el receptor. Este método le permite al crítico llegar a una serie de conclusiones interesantes, sobre todo en lo concerniente a la colectividad histórica y a la evolución de sus gustos literarios. Pero el hecho de aplicar al análisis de la Vida de Don Quijote y Sancho la teoría de la recepción, que rechaza abiertamente todo factor psicológico, impide explorar en la experiencia individual del receptor. En consecuencia, Maestro no hace referencia a las angustias existenciales de Unamuno, lo que lleva a unas conclusiones incompletas. De este modo, todo lo esencial del libro unamuniano queda fuera del interés del investigador. Me refiero a la crisis religiosa que sufrió Unamuno y que, con toda probabilidad, le empujó a escribir la Vida de Don Quijote y Sancho. Gracias a otros textos unamunianos — sobre todo a su Diario íntimo ${ }^{3}$ - sabemos que aquella vivencia fue trascendental tanto para su vida como para su obra literario-filosófica. La crisis — que sufrió a causa de la muerte de su hijo y su propia enfermedad ${ }^{4}$ - le llevó a preguntarse por la finalidad de la vida y la posibilidad de luchar contra la aniquilación del hombre después de la muerte. Su ansia de

${ }^{3}$ Un libro póstumo de Unamuno, publicado en 1966, en el que se recogen las experiencias más íntimas de la época de su grave crisis religiosa. Del libro se desprenden las zozobras existenciales de Unamuno: su temor a la muerte y su frenética búsqueda de Dios como garantía y única esperanza de inmortalidad.

${ }^{4}$ Los biógrafos indican el año 1897 como el momento en el que se produce la más grave de las crisis religiosas de Unamuno. Aquel año, el día 21 ó 22 de marzo el escritor sufre una neurosis cardíaca. Piensa que está al borde de la muerte. Al día siguiente se refugia en el convento de los dominicos. Entonces comienza una etapa de preocupaciones religiosas (http://www.unav.es/gep/CronologiaUnamuno. html). 
inmortalidad le hizo volver a las prácticas religiosas, abandonadas en su época de estudiante.

Las lecturas más evocadas en la Vida de Don Quijote y Sancho son una prueba de que Unamuno, en el momento de escribir su versión del libro cervantino, estaba buscando al Absoluto. Quería aliviar sus zozobras existenciales gracias al encuentro con Dios por medio de los personajes que representaban la fuerza y la misericordia divinas. Por eso, en la Vida de Don Quijote y Sancho hay constantes referencias a la Biblia y a la Vida de San Ignacio de Loyola, biografía realizada por Pedro Ribadeneyra. Es probable que gracias a estas lecturas Unamuno esperara conseguir reconciliarse con Dios. Lo cierto es que esos libros influyeron en la recepción y la valoración unamunianas de la novela de Cervantes. Así, para Unamuno, Don Quijote era un caballero de la fe, un santo laico, al igual que lo fue Santo Ignacio de Loyola. De hecho, los paralelos entre estos dos personajes son constantes a lo largo de la Vida de Don Quijote y Sancho. Según Unamuno, San Ignacio es un insuperable ejemplo de una vida santa y un excelente modelo a imitar. En el mismo tono se expresa, refiriéndose a Don Quijote. En los fragmentos en los que compara a ambos personajes, Unamuno parece experimentar una especie de exaltación mística:

¿No os recuerda esta salida [la primera salida de Don Quijote] la de aquel otro caballero, de la Milicia de Cristo, Iñigo de Loyola, que después de haber procurado en sus mocedades «de aventajarse sobre todos sus iguales y de alcanzar fama de hombre valeroso, y honra y gloria militar», y aun en los comienzos de su conversión, cuando se disponía a ir a Italia, siendo «muy atormentado de la tentación de la vanagloria», y habiendo sido, antes de convertirse, «muy curioso y amigo de leer libros profanos de caballerías», cuando después de herido en Pamplona leyó la vida de Cristo, y las de los Santos, comenzó a «trocársele el corazón y a querer imitar las obras que leía.» (VQS: 33)

Tal insistencia en comparar a ambos personajes nos lleva a suponer que la lectura de la obra de Cervantes y de la biografía de San Ignacio fue una especie de ejercicio espiritual al que se sometió Unamuno con la esperanza de recuperar su fe. La necesidad unamuniana 
de perfeccionarse se revela también en las frecuentes alusiones a los Ejercicios espirituales de San Ignacio de Loyola, otro texto que debió de dejar un fuerte impacto en la sensibilidad religiosa de Unamuno. Lo confirma Javier Blasco (2004: 64), convencido de que en la redacción de la Vida de Don Quijote y Sancho, el Quijote le sirvió a Unamuno de paradigma y los Ejercicios espirituales le proporcionaron el método.

La Biblia es otro libro al que Unamuno recurre constantemente. Reelaborando muchas de las aventuras del Quijote, a menudo cita fragmentos enteros o encuentra parecidos entre la vida del protagonista y la de Jesucristo. Por ejemplo, evocando el episodio de Roque Guinart reflexiona sobre el bien y el mal. Constata que el bien sale del mal, siendo su natural consecuencia. En esa ocasión recuerda a bandidos generosos de la historia española y a los malhechores de la Pasión de Jesucristo:

Cuando crucificaron Nuestro Señor Jesús Cristo, uno de los malhechores que estaba colgado junto a El, le injuriaba diciendo: «Si Tú eres el Cristo, sálvate a Ti mismo y a nosotros.» Y respondiendo el otro, reprendiéndole decía: «¿Ni aun tú temes a Dios estando en la condenación. Nosotros, a la verdad, justamente padecemos, porque recibimos lo que merecieron nuestros hechos, mas Este ningún mal hizo.» Y dijo a Jesús: «Señor, acuérdate de mí cuando fueres a tu reino.» Y entonces Jesús le dijo: «De veras te digo que hoy serás conmigo en el paraíso.» (Luc., XXIII, 39-43)

La justicia, la culpa y el castigo son otros temas a los que Unamuno dedica buena parte de su libro. El escritor aprovecha los numerosos episodios de personajes secundarios malvados para expresar su opinión al respecto. También allí la influencia de la Biblia es bastante destacable: según Unamuno, la justicia divina - aparentemente muy cruel- ofrece al pecador la esperanza de expiación y renovación espiritual. Don Quijote, igual que Dios, no castiga a los malhechores para saciar su ensañamiento sino para redimirlos. En opinión de Unamuno la justicia debe guiarse por la ley natural: el castigo debe ser inmediato a la culpa e ir acompañado del perdón: 
Los guardias que llevaban a los galeotes los llevaban fríamente, por oficio, en virtud de mandamiento de quien acaso no conociera a los culpables, y los llevaban a cautiverio. $\mathrm{Y}$ el castigo, cuando de natural respuesta a la culpa, de rápido reflejo a la ofensa recibida se convierte en aplicación de justicia abstracta, se hace algo odioso a todo corazón bien nacido. Nos hablan las Escrituras de la cólera de Dios o de los castigos inmediatos y terribles que fulminaba sobre los quebrantadores de su pacto, pero un cautiverio eterno, un penar sin fin basado en fríos argumentos teológicos sobre la infinitud de la ofensa y la necesidad de satisfacción inacabable, es un principio que repugna al cristianismo quijotesco. Bien está hacer seguir a la culpa su natural consecuencia [...] pero la última y definitiva justicia es el perdón. Dios, la naturaleza y Don Quijote castigan para perdonar. Castigo que no va seguido de perdón, ni se endereza a otorgarlo al cabo, no es castigo sino odioso ensañamiento. (VQS: 94)

Uno de los problemas fundamentales de la obra literario-filosófica de Miguel de Unamuno es la inmortalidad. En la Vida de Don Quijote y Sancho esta cuestión adquiere una gran relevancia: se indica el ansia de inmortalidad como el móvil de toda la acción de la novela cervantina. Según Unamuno, Don Quijote decide hacerse caballero andante porque anhela la inmortalidad. Esta interpretación revela otra diferencia entre la versión cervantina y la unamuniana de la historia quijotesca: lo que para Cervantes era luchar para ganar la fama, en Unamuno se convierte en una pugna por la inmortalidad. Además, Unamuno relaciona el ansia de inmortalidad con el amor platónico e irrealizable:

[...] del amor a mujer brota todo heroísmo. Del amor a mujer han brotado los más fecundos y nobles ideales, del amor a mujer las más soberbias fábricas filosóficas. En el amor a mujer arraiga, pues es en él donde el instinto de perpetuación vence y soyuga al de conservación [...] Ansia de inmortalidad nos lleva a amar a la mujer, y así fue como Don Quijote juntó en la Dulcinea a la mujer y a la Gloria, y ya que no pudiera perpetuarse por ella en hijo de carne, buscó eternizarse por ella en hazañas de espíritu. (VQS: 71-72) 
El escritor bilbaíno ahonda en este tema, preguntándose -en el texto el autor dialoga con el mismo Don Quijote- si no fue acaso el amor plátonico hacia Dulcinea el que le empujó a renunciar a su vida sedentaria y a buscar ocasiones para inmortalizarse. Así el amor y la gloria se juntan en la versión unamuniana de la historia de Don Quijote.

Como observa Maestro (1989: 254), en la Vida de Don Quijote y Sancho destacan cuatro grandes grupos temáticos:

1. Sobre la «lucha» en el hombre y su agitación espiritual.

2. Sobre la inmortalidad.

3. Sobre Dulcinea o el amor en don Quijote.

4. Sobre don Quijote y Sancho.

La importancia de las reflexiones sobre Don Quijote y Sancho Panza queda anunciada ya en el mismo título del libro. Unamuno, a diferencia de Cervantes, decide igualar a los dos protagonistas de la novela. Lo hace al colocar los nombres de ambos en el título y al atribuir a Sancho un papel parecido al de su amo. Aunque al principio de la Vida de Don Quijote y Sancho -igual que en la novela cervantinael escudero aparece como una figura complementaria de Don Quijote, su fiel compañero y su atento interlocutor, al final del libro adquiere una dimensión mística de la que gozó también su amo. Unamuno, en un arrebato de exaltación, se persuade de que Sancho continuará las obras de su amo. En él, pues, se depositan las virtudes del caballero muerto y se perpetúan sus más nobles ideales. En un ardiente discurso, dirigiéndose a Don Quijote, Unamuno exclama:

Sancho, que no ha muerto, es el heredero de tu espíritu, buen hidalgo, y esperamos tus fieles en que Sancho sienta un día que se le hincha de quijotismo el alma, que le florecen los viejos recuerdos de su vida escuderil, y vaya a tu casa y se revista de tus armaduras, que hará que se les arregle a su cuerpo y talla el herrero del lugar, y saque a Rocinante de su cuadra y monte en él, y embrace tu lanza, la lanza con que diste libertad a los galeotes y derribaste al Caballero de los Espejos, y sin hacer caso de las voces de tu sobrina, salga al campo y vuelva a la vida de las aventuras, convertido de escudero en caballero andante. Y entonces Don Quijote mío, entonces es cuando tu espíritu se asentará en la tierra. (VQS: 276) 


\section{Conclusiones}

La Vida de Don Quijote y Sancho de Miguel de Unamuno es una excelente prueba de la absoluta libertad del lector en el acto de la lectura y la interpretación de una obra literaria. La versión unamuniana de la historia de Don Quijote y Sancho Panza nos lleva a descubrir una sorprendente riqueza interpretativa de la novela cervantina. Unamuno desentraña los significados que en su opinión permanecían ocultos y que para él constituían lo más valioso de la novela de Cervantes: sus valores humanos y religiosos. La lectura del Quijote le ofreció a Unamuno una ocasión para ahondar en los problemas que tanto le atormentaban desde 1897, el año de su grave crisis religiosa.

En la Vida de Don Quijote y Sancho, las reflexiones se llevan a cabo en un tono espiritual, casi místico, muy distinto al tono de la novela cervantina. Mientras los protagonistas del Quijote se muestran más bien discretos en cuestiones de religión, en el libro de Unamuno se les concede un papel evangelizador y una misión redentora. ¿Es acertada o no la interpretación unamuniana del Quijote? A esta pregunta cada lector puede responder personalmente. Lo cierto es que la Vida de Don Quijote y Sancho es una atrevida refundición de la novela cervantina, siendo al mismo tiempo un emocionante retrato espiritual de Don Miguel de Unamuno.

\section{Bibliografía}

BLASCO, J. (2004), "La Vida de don Quijote y Sancho o lo que habría ocurrido "si don Quijote hubiese en tiempo de Miguel de Unamuno vuelto al mundo", en: Letras hispanas, 1, 1, pp. 55-69.

Cronología de Miguel de Unamuno (2009), [on-line] http://www.unav.es/gep/ CronologiaUnamuno.html, 8.08.2016.

GULLÓN, R. (1987), "Introducción", en: M. de Unamuno, Vida de Don Quijote y Sancho, Alianza, Madrid, pp. I-XVIII.

LÓPEZ-PARSÍN BASABE, A. (2009), "En torno a la Vida de Don Quijote y Sancho, de Unamuno: cuestiones de hermenéutica", en: Cuad. Cát. M. de Unamuno, 47, 2, pp. 53-67. 
MAESTRO, J.G. (1989), "Miguel de Cervantes, Miguel de Unamuno: El Quijote desde la experiencia de la estética de la recepción de 1898”, en: Actas II-Asociación de Cervantistas, pp. 241-264.

RUBIA PRADO, F. la (1999), Unamuno y la vida como ficción, Gredos, Madrid.

UNAMUNO, M. de (1989 [1905]), Vida de Don Quijote y Sancho, Alianza Editorial, Madrid.

UNAMUNO, M. de (2006 [1966]), Diario íntimo, Alianza Editorial, Madrid. 